\title{
Summary of 1993 World Health Organisation-International Society of Hypertension guidelines for the management of mild hypertension
}

\author{
Subcommittee of WHO/ISH Mild Hypertension Liaison Committee
}

As part of the ongoing process of issuing guidelines for managing hypertension the World Health Organisation and International Society of Hypertension present a summary of the latest guidelines for the management of mild hypertension. In both young and elderly people this condition is a risk factor for cardiovascular disease and should be treated. Information is presented on methods of diagnostic evaluation and assessment of risk. Methods of treatment, including changes in lifestyle, are covered.

The World Health Organisation and the International Society of Hypertension are periodically issuing guidelines for the management of mild hypertension. A consensus document with the third revision of these guidelines has been finalised recently and is being published in journals specifically devoted to hypertension. This paper presents a condensed version of this consensus document so that the essential message can reach the wider audience of practising doctors who are responsible for the care of patients with hypertension.

These guidelines concentrate on mild hypertension as this condition often presents a diagnostic and therapeutic problem, and evidence for benefit in treating more severe hypertension is clear. In this revision emphasis is also placed on systolic blood pressure as a criterion for decision making and on hypertension in elderly people, another condition in which careful judgment is necessary. Information is provided on useful methods for diagnostic evaluation and the assessment of cardiovascular risk. Additional information is provided on treatment with and without drugs and on the correction of other major risk factors for cardiovascular disease.

When preparing these guidelines the subcommittee was aware that there are clear differences between individual patients with similar degrees of hypertension that have important implications for decisions about treatment. Accordingly, guidelines should not be seen as rigid constraints on a practising doctor's decisions. Guidelines should provide extensive, critical, and well balanced information on benefits and limitations of the various diagnostic and therapeutic interventions so that the physician may exert the most careful judgment in individual cases. Although the most reliable information is that provided by large randomised trials, these have their own limitations and not all aspects of the management of hypertension have been or can be determined by the results of randomised trials. Scientifically sound interpretation and cautious extrapolation of existing data can also affect clinical decision making.

\section{Assessment of cardiovascular risk in patients with hypertension}

There is a continuum of cardiovascular risk associated with the level of blood pressure: the higher the blood pressure the higher the risk of both stroke and coronary events. ${ }^{1}$ The dividing line between normotension and hypertension is arbitrary. The current definition is that this line is the blood pressure above which intervention has been shown to reduce the risk. ${ }^{2}$ It is well established that lowering even mildly raised pressures reduces morbidity and mortality from cardiovascular disease. ${ }^{3}$ A decision to intervene, however, should not depend on blood pressure alone.

Indeed, among people with mild hypertension the risk of serious cardiovascular disease is also determined by several factors other than blood pressure. These include increasing age, male sex, previous cardiovascular events, target organ damage (such as left ventricular hypertrophy or renal disease), smoking, diabetes, dyslipidaemia (high concentrations of total and low density lipoprotein cholesterol, low concentrations of high density lipoprotein cholesterol), central obesity, and sedentary lifestyle. ${ }^{4}$ The presence of one or more of these factors may be a more important determinant of risk than a mild increase in blood pressure. Since the absolute benefits of antihypertensive treatment will be determined by the absolute risk of cardiovascular disease (that is, greater benefits among those at higher risk) each of these factors should be assessed before making decisions about treatment.

The absolute risk of serious cardiovascular disease varies greatly among people with mild hypertension. At one extreme at least three to five in every 100 elderly patients with a history of cardiovascular disease will suffer a further serious event each year..$^{5-8}$ At the other extreme fewer than one in every 1000 young people with no other risk factors will suffer a serious event each year. ${ }^{9}$ Although antihypertensive treatment will reduce risks in both these groups of patients, it may take some decades for clinical benefits to become apparent in young patients at low initial risk.

\section{Definition and classification of hypertension} BLOOD PRESSURE MEASUREMENT

Blood pressure is generally measured by the indirect method with a mercury sphygmomanometer. Before measurement the patient should be seated for several minutes in a quiet room. A cuff of suitable size is applied evenly to the upper arm kept at heart level. The cuff is rapidly inflated until the manometer reading is about $30 \mathrm{~mm} \mathrm{Hg}$ above the level at which the pulse disappears and then slowly deflated at about $2 \mathrm{~mm} \mathrm{Hg} / \mathrm{s}$. During this time the Korotkoff sounds are auscultated through a stethoscope placed over the brachial artery. The pressure at which the sounds are first heard is the systolic pressure; the diastolic pressure is the pressure at which the sounds disappear (phase V).

"White coat hypertension" or "effect" is a condition in which blood pressure is raised only in the presence of a doctor. Measurement by nurses or trained nonmedical staff may reduce but not necessarily abolish 
Management of mild hypertension (diastolic blood pressure $90-105 \mathrm{~mm} \mathrm{Hg}$ or systolic blood pressure $140-180 \mathrm{~mm} \mathrm{Hg}$, or both)

Blood pressure measured at least twice on two different occasions: if mean values are 90-105 (diastolic pressure) and/or 140-180 (systolic pressure) $\mathrm{mm} \mathrm{Hg}$

\begin{tabular}{|c|c|c|}
\hline $\begin{array}{l}\text { After four } \\
\text { weeks }\end{array}$ & $\begin{array}{l}\text { Repeat measurements on } \\
\text { at least two further occasions } \\
\text { over period of four weeks }\end{array}$ & \\
\hline $\begin{array}{c}\text { Blood pressure }<140 / 90 \mathrm{~mm} \mathrm{Hg}: \\
\text { Further measurements every } \\
\text { three months for I year }\end{array}$ & \multicolumn{2}{|c|}{$\begin{array}{l}\text { Diastolic pressure } 90-105 \text { and/or systolic } \\
\text { pressure } 140-180 \mathrm{~mm} \mathrm{Hg:} \mathrm{institute} \mathrm{non-drug} \\
\text { treatment and monitor blood pressure }\end{array}$} \\
\hline \multicolumn{3}{|l|}{$\begin{array}{l}\text { After first } \\
\text { three months }\end{array}$} \\
\hline $\begin{array}{l}\text { Diastolic pressure } 90-95 \\
\text { and/or systolic pressure } \\
\text { 140-160 } \mathrm{mm} \mathrm{Hg:} \\
\text { reinforce non-drug measures } \\
\text { and monitor blood pressure }\end{array}$ & $\begin{array}{l}\text { Diastolic pressure } 95-100 \\
\text { and/or systolic pressure } \\
160-180 \mathrm{~mm} \mathrm{Hg:} \\
\text { reinforce non-drug measures } \\
\text { and consider drug treatment } \\
\text { if other risk factors present }\end{array}$ & $\begin{array}{l}\text { Diastolic pressure } \\
\geqslant 100 \mathrm{~mm} \mathrm{Hg} \text { or systolic } \\
\text { pressure } 160-180 \mathrm{~mm} \mathrm{Hg} \text { with } \\
\text { diastolic pressure } \geqslant 95 \mathrm{~mm} \mathrm{Hg} \text { : } \\
\text { reinforce non-drug measures } \\
\text { and institute drug treatment }\end{array}$ \\
\hline \multicolumn{3}{|l|}{$\begin{array}{l}\text { After second } \\
\text { three months }\end{array}$} \\
\hline $\begin{array}{c}\text { Diastolic pressure } 90-95 \\
\text { and/or systolic pressure } \\
140-160 \mathrm{~mm} \mathrm{Hg} \text {, } \\
\text { no other risk factors: } \\
\text { continue non- drug treatment } \\
\text { and monitor blood pressure }\end{array}$ & $\begin{array}{l}\text { Diastolic pressure } 90-95 \\
\text { and/or systolic pressure } \\
140-160 \mathrm{~mm} \mathrm{Hg}, \\
\text { with other risk factors: } \\
\text { consider } \\
\text { drug treatment }\end{array}$ & $\begin{array}{l}\text { Diastolic pressure } 95-100 \\
\text { and/or systolic pressure } \\
160-180 \mathrm{~mm} \mathrm{Hg} \text {, } \\
\text { with or without other risk } \\
\text { factors: } \\
\text { institute drug treatment }\end{array}$ \\
\hline
\end{tabular}

Note: Institute drug treatment more promptly in patients with evidence of substantial risk of cardiovascular disease or in patients with blood pressure above mild hypertension range

this effect. ${ }^{10}$ Whether the effect is an innocent phenomenon is unknown. Indeed, it has been suggested that subjects showing a more distinct difference between measurement in the clinic and home may be at somewhat higher cardiovascular risk. ${ }^{11}$ It is important, however, to recognise the condition to avoid unnecessary treatment in many subjects.

Semiautomatic and automatic devices for measurement at home and for prolonged ( 24 hours or more) ambulatory monitoring are now available. ${ }^{12}$ Measurement of blood pressure at home has the potential advantage of providing more numerous readings and in a quieter setting than measurement in the doctor's office. Ambulatory monitoring of blood pressure is an interesting research technique which is used to investigate variability in blood pressure, behavioural influences on arterial pressure, and the time course of effects of antihypertensive treatment. It is also used, as are home readings, to provide a supplementary source of information for diagnostic and therapeutic decisions. ${ }^{12}$ Home and ambulatory blood pressures, however, cannot be equated to readings taken by the conventional method in the clinic by physicians or nurses. There is evidence supported by a recent population survey that both home and ambulatory readings averaged over 24 hours are several $\mathrm{mm} \mathrm{Hg}$ lower than values measured in the clinic ( $\mathrm{R}$ Sega et al, 6th European meeting on hypertension, Milan, 1993). Prognostic standards with regard to treatment have been based on prospective studies relating casual or

TABLE I-Classification of hypertension by blood pressure

\begin{tabular}{|c|c|c|c|}
\hline Classification & $\begin{array}{l}\text { Systolic } \\
\text { blood pressure } \\
(\mathrm{mm} \mathrm{Hg})\end{array}$ & & $\begin{array}{l}\text { Diastolic } \\
\text { blood pressure } \\
(\mathrm{mm} \mathrm{Hg})\end{array}$ \\
\hline $\begin{array}{l}\text { Normal } \\
\text { Mild hypertension } \\
\text { Subgroup: borderline hypertension } \\
\text { Moderate and severe hypertension` } \\
\text { Isolated systolic hypertension } \\
\text { Subgroup: borderline isolated systolic hypertension }\end{array}$ & $\begin{aligned} & <140 \\
140-180 & \\
140-160 & \\
\geqslant & 180 \\
\geqslant & 140 \\
140-160 & \end{aligned}$ & $\begin{array}{l}\text { and } \\
\text { and/or } \\
\text { and/or } \\
\text { and/or } \\
\text { and } \\
\text { and }\end{array}$ & $\begin{aligned} & <90 \\
& 90-105 \\
90-95 & \geqslant 105 \\
& <90 \\
<90 & \end{aligned}$ \\
\hline
\end{tabular}

${ }^{\star}$ Risk to be indicated by reporting actual values of systolic and diastolic blood pressure. clinic measurements of blood pressure to morbidity and mortality. No prospective studies are available providing prognostically valuable standards for home or ambulatory readings. For the time being, these measurements should be used only in selected cases to complement the values measured by the physician.

\section{DEFINITION OF MILD HYPERTENSION}

Most of the randomised therapeutic trials on hypertension, including those on mild hypertension, have defined and treated patients on the basis of diastolic blood pressure values, and for this reason diastolic blood pressure has generally been used to define mild hypertension. There is, however, mounting evidence that systolic values should also be taken into account in defining and managing hypertension..$^{13}$ Indeed, cardiovascular risk is as strongly associated with systolic as with diastolic values, with no evidence of a threshold below which a decrease in pressure does not reduce risk. ${ }^{14}$ Furthermore, some of the intervention studies on mild hypertension indicate that cardiovascular events more closely correlate with achieved systolic than with diastolic values. ${ }^{15}$

These guidelines therefore define mild hypertension on the basis of diastolic and systolic blood pressure values. The figure shows a flow chart of decision making based on systolic and diastolic pressures. In summary, a diagnosis of mild hypertension can be made when diastolic blood pressure values of $90-105 \mathrm{~mm} \mathrm{Hg}$ or systolic values between 140-180 $\mathrm{mm} \mathrm{Hg}$, or both, are repeatedly measured over at least four weeks, and at this time only nonpharmacological intervention is to be recommended. After three additional months of observation drug treatment should be instituted if diastolic blood pressure is at least $100 \mathrm{~mm} \mathrm{Hg}$ (irrespective of systolic values) or if systolic blood pressure is between $160-180 \mathrm{~mm} \mathrm{Hg}$ with diastolic values of at least $95 \mathrm{~mm} \mathrm{Hg}$ or with diastolic values below $95 \mathrm{~mm} \mathrm{Hg}$ if other cardiovascular risk factors are present. After a second period of three months persistent diastolic pressures between 95 and $100 \mathrm{~mm} \mathrm{Hg}$ or persistent systolic pressures between $160-180 \mathrm{~mm} \mathrm{Hg}$, or both, may justify drug treatment. At this time even diastolic values between 90 and $95 \mathrm{~mm} \mathrm{Hg}$ or systolic values between 140 and $160 \mathrm{~mm} \mathrm{Hg}$, or both, may deserve drug treatment if other substantial risk factors are present.

In most cases both values will be in the respective ranges for mild hypertension, but in other cases either isolated mild diastolic hypertension or isolated mild systolic hypertension may occur. Isolated systolic hypertension may be found in adolescent and young people but is particularly common in elderly people. There is no evidence that isolated mild systolic hypertension in adolescent and young people should be treated other than with lifestyle counselling. On the other hand, isolated systolic hypertension in elderly people (often beyond the mild range) not only carries additional risk ${ }^{14}$ but has recently been shown to benefit considerably from pharmacological reduction of raised systolic blood pressure.

\section{CLASSIFICATION OF HYPERTENSION}

Table I shows an operational classification of hypertension by blood pressure based on the considerations above as a practical guide to management. It does not classify subjects with diastolic blood pressure between 85 and $89 \mathrm{~mm} \mathrm{Hg}$ or systolic blood pressures between 130 and $139 \mathrm{~mm} \mathrm{Hg}$ as "high normal" 16 as this does not seem justified at the moment and carries the risk of labelling a large number of subjects. Table II is a classification of hypertension according to extent of organ damage. As suggested in the 1978 WHO's expert report, ${ }^{17}$ the term "stage" is used to indicate the 


\begin{tabular}{|c|c|}
\hline Stage & Sign \\
\hline I & $\begin{array}{l}\text { No objective signs of organic changes } \\
\text { At least one of following signs of organ damage: } \\
\text { left ventricular hypertrophy ( } x \text { ray film, electrocardiogram, } \\
\text { echocardiogram) } \\
\text { generalised and focal narrowing of retinal arteries } \\
\text { proteinuria or slightly raised plasma creatinine concentration } \\
\text { (106-177 } \mu \text { mol/), or both } \\
\text { ultrasound or radiological evidence of atherosclerotic plaque } \\
\text { (carotid arteries, aorta, iliac and femoral arteries) }\end{array}$ \\
\hline III & $\begin{array}{l}\text { Both symptoms and signs have appeared as result of organ damage, } \\
\text { including } \\
\text { heart-angina pectoris, myocardial infarction, heart failure } \\
\text { brain-transient ischaemic attack, stroke, hypertensive } \\
\text { encephalopathy } \\
\text { optic fundi-retinal haemorrhages and exudates with or } \\
\text { without papilloedema } \\
\text { kidney-plasma creatinine concentration }>177 \mu \mathrm{mol} / \text {, renal } \\
\text { failure } \\
\text { vessels-dissecting aneurysm, symptomatic arterial occlusive } \\
\text { disease }\end{array}$ \\
\hline
\end{tabular}

absence, presence, or severity of complications rather than to substitute blood pressure values.

\section{Treatment: general concepts}

EFFECTS OF ANTIHYPERTENSIVE TREATMENT ON RISKS OF CARDIOVASCULAR EVENTS

Randomised controlled trials have shown that in patients with mild hypertension lowering of blood pressure with antihypertensive drugs decreases morbidity and mortality from cardiovascular disease. On average the 5-6 $\mathrm{mm} \mathrm{Hg}$ reduction in diastolic blood pressure (and $10 \mathrm{~mm} \mathrm{Hg}$ reduction in systolic blood pressure) reduced the risk of stroke by about a third and the risk of coronary events by about a sixth. ${ }^{3}$ The benefits of antihypertensive treatment, however, have probably been underestimated by most of the randomised controlled trials for at least three reasons. Firstly, in many trials of active versus placebo treatment there has been extensive cross over of patients from placebo to active treatment. Secondly, in severa trials patients at low risk were preferentially included. Finally, most trials have been fairly short term (three to five years' duration) and the full effects of reduction of blood pressure on coronary events in particular may take a decade or more to become manifest. Since the absolute risk of coronary events in young patients is low the initial goals of treatment are to prevent the progression of disease processes, such as left ventricular hypertrophy and possibly atherosclerosis, rather than discrete events. ${ }^{18}$

\section{FACTORS INFLUENCING INITIATION OF TREATMENT}

Diastolic and systolic blood pressures are important for initiation of treatment, and we emphasise that whenever blood pressures are above the mild hypertension range (that is, systolic 180 and diastolic $105 \mathrm{~mm} \mathrm{Hg}$ or above; see table I) a decision to treat with drugs should be taken after a shorter observation period than the one suggested in the figure.

Several factors other than diastolic and systolic blood pressures, however, may influence the decision to begin drug treatment. The following factors indicate early pharmacological treatment of hypertension. Firstly, treatment should be considered sooner in men and postmenopausal women. Secondly. the presence of cardiovascular complications such as left ventricular hypertrophy (an important predictor of subsequent cardiovascular events ${ }^{1920}$ ) evidence of ischaemic heart disease, and history of cerebrovascular disease should encourage treatment. Thirdly, raised serum creatinine concentration and proteinuria, which are predictors not only of renal impairment but also of cardiovascular events should also lead to early treatment. ${ }^{21}$ Fourthly, diabetes is a potent additional risk factor in hypertension and vice versa. The presence of microalbuminuria is an early indicator of this increase in risk. ${ }^{22}$ Treatment of high blood pressure or even lowering normal blood pressure in diabetic patients reduces microalbuminuria and, when present, proteinuria; slows the decline in renal function; and delays the development of diabetic nephropathy. ${ }^{23}$ Fifthly, early treatment should be considered in the presence of other cardiovascular risk factors-such as continued cigarette smoking, raised fasting glucose concentration, raised serum concentration of total cholesterol, and low concentration of high density lipoprotein cholesterolwhich appreciably increase the cardiovascular risk associated with high blood pressure ${ }^{4}$ and increase the absolute benefit of lowering blood pressure. Sixthly, treatment may be initiated sooner in patients with a family history of hypertension, premature stroke, heart disease, or sudden cardiac death.

In those from low income populations a decision to initiate drug treatment and, more broadly, the range of actions desirable for control of hypertension will vary with a population's resources, constraints, mortality structure, and the resulting priorities in health care. In developing countries costs may make it difficult to extend all choices of diagnostic procedures and drug treatments to all people with mild hypertension. Although people at higher risk should be treated pharmacologically, careful choice of drugs with increased emphasis on cost effectiveness becomes particularly important with growing economic constraints. Increasing the public's awareness of the hazards of hypertension, measuring blood pressure at every opportunity (and specifically on the occasion of any medical visit independently of the cause of the visit), regular surveying of people with hypertension, and educating the population about factors that may raise blood pressure or aggravate existing hypertension are measures as important in low income as in affluent populations.

\section{HYPERTENSION IN ELDERLY PEOPLE}

In absolute terms hypertension is a much greater risk factor for cardiovascular events in elderly people

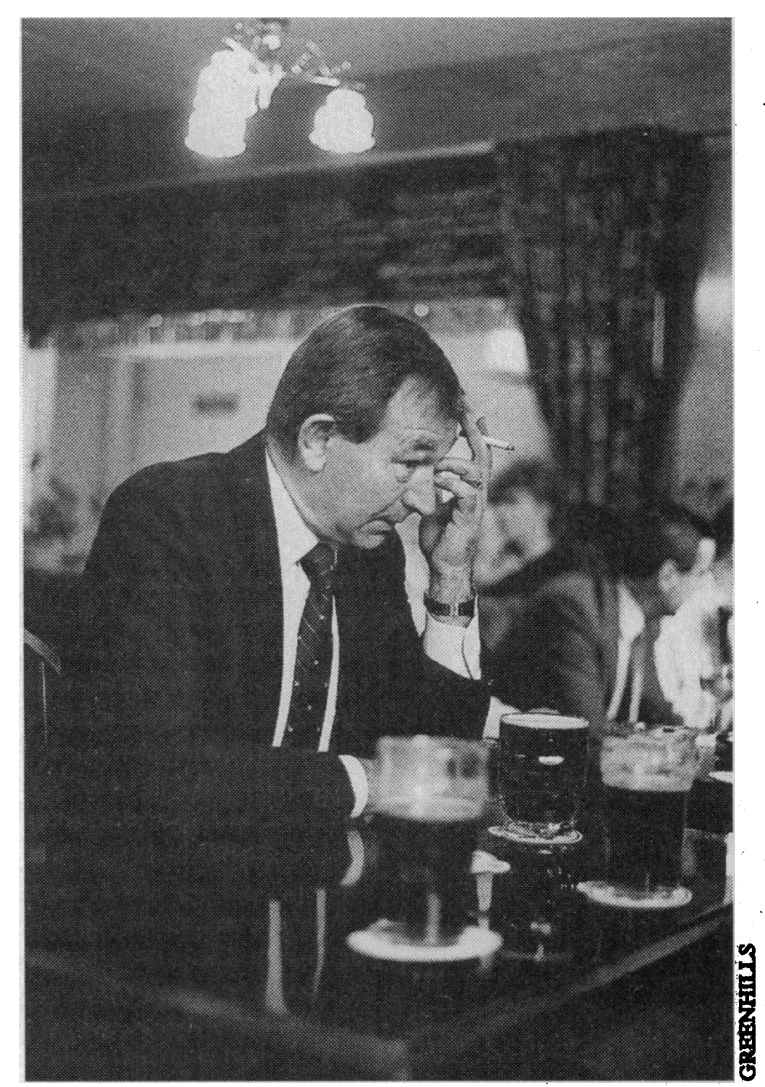

Changes in lifestyle should be the first step in treating mild hypertension

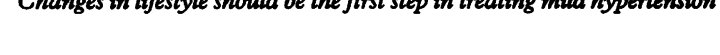


than in younger people. Among those with mild hypertension in Western populations the 10 year risk of a major cardiovascular event ranges from less than $1 \%$ in those aged $25-34$ years to more than $30 \%$ in those aged $65-74$ years. ${ }^{4}$ Correspondingly, numerous intervention trials have shown that the absolute benefit of antihypertensive treatment is particularly high in elderly people.

In addition to the results of the trial of the European working party on high blood pressure in the elderly published in $1985,{ }^{5}$ which clearly showed the beneficial effect of antihypertensive drug treatment in elderly people, the results of three prospective placebo controlled therapeutic trials in elderly people with hypertension have been reported in 1991 and 1992 . All showed significant reduction of cardiovascular morbidity or mortality. The systolic hypertension in the elderly programme specifically examined the value of antihypertensive treatment in elderly men and women with isolated systolic hypertension; highly significant reductions in fatal and non-fatal cardiovascular events were observed. ${ }^{6}$

From the results of all these trials it is obvious that antihypertensive treatment in elderly patients with hypertension, be it isolated systolic or combined systolic and diastolic, provides relative benefits in terms of percentage reduction in cardiovascular morbidity and mortality that are of at least the same magnitude (about $20-50 \%$ ) as the benefits of treatment in young and middle aged patients with hypertension. Since the incidence of cardiovascular events is high in elderly people, however, the same relative reduction in risk as in younger patients provides a greater absolute benefit in this age group. In all trials with the single exception of the Medical Research Council trial ${ }^{8}$ benefit ranges between one event prevented each year for every 35 treated patients and one event prevented for every 90 treated patients. Old age, therefore, renders antihypertensive treatment particularly beneficial. According to the Swedish trial in old patients with hypertension (STOP hypertension) significant benefits are also seen in the very elderly without any clear upper limit. $^{7}$

\section{GOAL OF TREATMENT}

Since the relation between blood pressure and cardiovascular risk is continuous it seems appropriate for the goal of treatment to be the maximum tolerated reduction in blood pressure. There is good evidence from epidemiological studies that within the normal range of both systolic and diastolic blood pressures the lower the blood pressure the lower the risks of both stroke and coronary events. ${ }^{1}$ The claim that lowering diastolic blood pressure below $85 \mathrm{~mm} \mathrm{Hg}$, at least in particular groups of patients (such as those with ischaemic heart disease), raises the risk above that associated with a more moderate reduction in blood pressure ${ }^{24}$ is unproved but is currently being tested in a randomised trial..$^{25}$

On the basis of available evidence it is desirable to achieve blood pressures of at least $120-130 / 80 \mathrm{~mm} \mathrm{Hg}$ in young patients with mild hypertension. In elderly patients with raised systolic and diastolic blood pressure it is desirable to lower blood pressure to below $140 / 90 \mathrm{~mm} \mathrm{Hg}$, and in patients with isolated systolic hypertension the goal of treatment should be to achieve a systolic blood pressure of at least $140 \mathrm{~mm} \mathrm{Hg}$ if this is tolerated. When home blood pressure or ambulatory blood pressure measurements are used to help in evaluating blood pressure achieved by treatment it should be remembered that values provided by these methods are on the average several $\mathrm{mm} \mathrm{Hg}$ lower than clinic blood pressures ( $\mathrm{R}$ Sega et al, 6th European meeting on hypertension). When blood pressure is assessed by these techniques the treatment goal should therefore be set at a lower level to avoid undertreatment.

\section{Modes of treatment}

NON-PHARMACOLOGICAL INTERVENTIONS

Several non-pharmacological interventions are recommended in primary prevention of hypertension and other cardiovascular diseases and have been the object of a recent joint WHO-ISH document on this issue. ${ }^{26}$ These interventions have also been shown to lower blood pressure in patients with mild hypertension. Reduction of weight in overweight subjects, reduction of alcohol consumption to no more than 20-30 g ethanol a day, regular mild (not strenuous) exercise in sedentary subjects (such as walking, jogging, cycling, or swimming), and restriction of sodium chloride intake to no more than $5 \mathrm{~g}$ a day at least in some patients are effective in lowering blood pressure. It is known, however, that these modifications of lifestyle are difficult to apply at large, that compliance to such recommendations is poor in the long term, and that the ability of non-pharmacological interventions to reduce mortality and morbidity in hypertension has not been proved directly. Nevetheless, it seems reasonable to advise that efforts to lower blood pressure by modifications in lifestyle should normally precede any drug treatment for mild hypertension.

CONTROL OF ASSOCIATED RISKS

Tobacco-All the large scale trials of treatment of mild hypertension have confirmed that treated patients who smoke tobacco have a greater incidence of both stroke and coronary heart disease than those who do not smoke. Repeated advice on how to stop smoking is therefore of major importance and will need to be coupled with particular efforts to prevent consequent weight gain.

Lipids-As high serum cholesterol concentrations and diabetes also unfavourably influence the long term prognosis of people with hypertension, nutritional counselling and, when appropriate, drug treatment, are indicated to control these risk factors. As increased physical activity is also likely to reduce the risk of cardiovascular disease it is appropriate in such patients.

Oral contraceptives and hormone replacement therapyAlternative methods of contraception should be considered for women with hypotension in place of oral contraceptives that contain oestrogen-progesterone as these substances may raise blood pressure as well as carry other cardiovascular risks. ${ }^{27}$ Hormone replacement therapy is being increasingly used to prevent osteoporosis in postmenopausal women. There is evidence that replacement with oestrogen alone reduces coronary risk ${ }^{28}$ but less evidence for this with combined oestrogen-progesterone treatment. There is no contraindication to the use of hormone replacement therapy in women with hypertension but blood pressure should be monitored more frequently as hypertensive responses may occur in some women.

\section{ANTIHYPERTENSIVE DRUGS}

Randomised trials of antihypertensive treatment have shown the benefits of lowering blood pressure. Although most of these trials have used diuretics, centrally acting drugs, vasodilators, or $\beta$ blockers, often in combination, no evidence is so far available that benefits are due to any particular class of antihypertensive agents rather than to the lowering of blood pressure itself. Also in several of the recent trials of antihypertensive treatment in elderly people as many as $60-70 \%$ of the patients receiving active treatment took a combination of two or more drugs, and the real evidence provided by these trials is about the benefit of lowering blood pressure. 


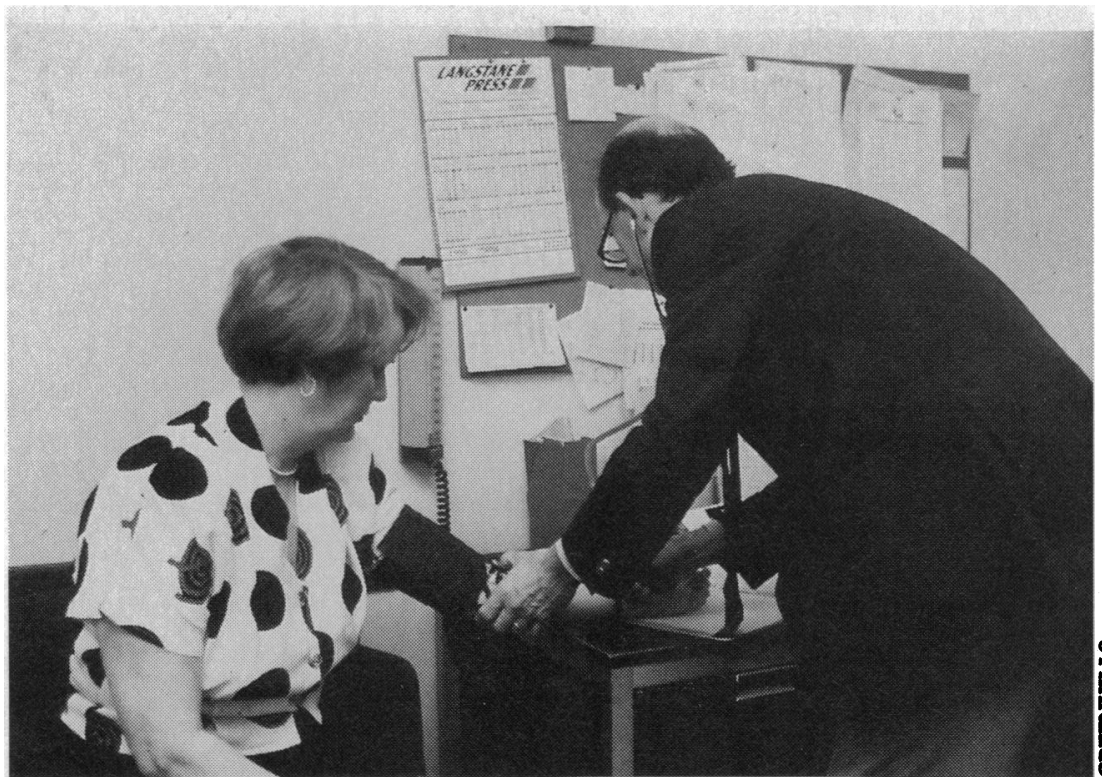

Patients need to be seen regularly until blood pressure is satisfactority controlled

Several classes of drugs can be recommended as first line treatment of mild sustained hypertension. They may be listed in order of proved benefit based on mortality-morbidity studies as, firstly, diuretics; secondly, $\beta$ blocking drugs; and, thirdly, angiotensin converting enzyme inhibitors, calcium antagonists, and $\alpha$ adrenoceptor blocking drugs.

The average reduction in blood pressure induced in groups of patients by each of the different categories of drugs is similar, but there are large variations in the reductions in individual patients. The appropriate choice of a particular class of antihypertensive drugs for a patient may also be determined by the person's other characteristics because differences in the risk profile and in side effects are extensive in different patients.

The choice of the initial drug treatment for an individual patient is a challenge for the physician and should not be restricted on theoretical or economical grounds to any one or two of the various classes of drugs which have been tested so far, although it is also the physician's responsibility to give due consideration to cost.

Finally, we should bear in mind that the hard evidence of benefit (risk ratios for mortality, stroke, and coronary events) has been obtained largely over a relatively short time (of about $2 \frac{1}{2}$ years to the end point). Such end points may not be relevant for younger patients with hypertension, who may have decades of treatment ahead of them. For such patients a reduction in progression of cardiovascular lesions may be more relevant. ${ }^{1829}$

\section{COMBINATIONS OF DRUGS}

If treatment with one compound of any of the five major pharmacological classes mentioned above has been found ineffective in lowering blood pressure in a given patient it is reasonable to substitute the first drug with a compound belonging to a different class. If a single drug has been partly effective it may be preferable to add a small dose of a second drug rather than to increase the dose of the first.

Effective combinations contain compounds from different groups of drugs. This permits the addition of different primary actions while minimising the homoeostatic compensations that limit the fall in pressure. Combination treatment also minimises side effects by encouraging the use of drugs in low doses. An additive effect has been shown with combinations of a diuretic with a $\beta$ blocker or an angiotensin con- verting enzyme inhibitor or an $\alpha$ blocker; a $\beta$ blocker with an $\alpha$ blocker or a dihydropyridine calcium antagonist; and an angiotensin converting enzyme inhibitor with a calcium antagonist.

To achieve the full goal of antihypertensive treatment in all hypertensive patients (that is, the maximum tolerated reduction in blood pressure) combinations of two and sometimes three drugs may be required.

\section{Follow up}

During the stabilisation period of treatment patients need to be seen at regular intervals until blood pressure is satisfactorily controlled. The main task of doctors during follow up is to ensure that the target systolic and diastolic blood pressure is reached and maintained and that other risk factors are controlled. Gradual and careful lowering of blood pressure will minimise side effects and complications and will improve compliance. Sometimes telling a patient that he or she has hypertension ("labelling") may be followed by anxiety or mood changes. Additional support-for example, reassurance about prognosis, emphasis on the ability to lead normal active lives, and explanation of any new symptoms that may appear-is therefore particularly important. Self measurement of blood pressure may be helpful to ensure compliance. After stabilisation of blood pressure follow up visits at intervals of three to six months may be adequate.

As a rule antihypertensive treatment should be maintained indefinitely. If patients who have been correctly diagnosed as having hypertension (see criteria above and flow chart) stop treatment their blood pressure usually returns to pretreatment levels sooner or later. Nevertheless, after prolonged control of blood pressure it may be possible to attempt a careful progressive reduction in the dose or number of drugs used, especially in patients strictly observing non-drug treatment. Attempts to step down treatment should be accompanied, however, by careful, continued supervision of blood pressure. Depending on the drugs used, appropriate laboratory investigations should be performed at regular intervals.

\section{Cost effectiveness}

The cost effectiveness of treating hypertension varies considerably with the degree of cardiovascular risk in various subgroups of patients with hypertension. The cost effectiveness is more apparent in elderly subjects and in patients with previous cardiovascular disease. The benefit is realised within a shorter time span than it is in younger patients-in whom the benefit is delayed for many years, during which the costs of management accumulate. On the other hand, the costs of treating cardiovascular complications of hypertension such as stroke make the treatment of hypertension a cost effective process in high risk groups, in whom the incidence of stroke is reduced by over $40 \%$

Whereas the costs of expensive diagnostic procedures and drugs are readily identified in high risk groups, doctors should give careful consideration to the costs associated with the investigation and treatment of patients with mild hypertension without associated risk factors. Primary prevention of hypertension and strategies based on changing the lifestyle of the whole population may offer the most cost effective means of reducing the morbidity and mortality associated with mild hypertension. The effectiveness of these approaches in primary prevention requires further validation.

These guidelines are a consensus document prepared by the guidelines subcommittee of the WHO/ISH Mild Hyperten- 
sion Liaison Committee. They represent the third revision of the WHO-ISH guidelines and were finalised after presentation and discussion at the 6th WHO/ISH meeting on mild hypertension, Chantilly, France, 28-31 March 1993. The full text of the guidelines is published in the Fournal of Hypertension 1993;11:905-18. The previous WHO/ISH guidelines were published in Bull WHO 1989;67:493-8 and $\mathcal{F}$ Hypertens 1989;7:689-93.

1 MacMahon S, Peto R, Cutler J, Collins R, Sorlie P, Neaton J, et al. Blood pressure, stroke and coronary heart disease. Part 1 . Prolonged differences in
blood pressure: prospective observational studies corrected for the regression dilution bias. Lancet 1990;335:765-74.

2 Evans JG, Rose G. Hypertension. Br Med Bull 1971;27:37-42.

3 Collins R, Peto R, MacMahon S, Hebert P, Fiebach NH, Eberlein KA, et al. Blood pressure, stroke, and coronary heart disease. Part 2. Short-term reductions in blood pressure: overview of randomised drug trials in their epidemiological context. Lancet 1990;335:827-38.

4 Kannel WB. Hypertension and the risk of cardiovascular disease. In: Laragh $\mathrm{JH}$, Brenner BM, eds. Hypertension: pathophysiology, diagnosis, and management. New York: Raven Press, 1990:101-17.

5 Amery $\mathrm{A}$, Birkenhăger $\mathrm{W}$, Brixko $\mathrm{P}$, Bulpitt $\mathrm{C}$, Clement $\mathrm{D}$, Deruyttere $\mathrm{M}$, et al. Mortality and morbidity results from the European working party on high blood pressure in the elderly trial. Lancet 1985;i:1349-54.

6 SHEP Cooperative Research Group. Prevention of stroke by antihypertensive drug treatment in older persons with isolated systolic hypertension. FAMA 1991;265:3255-64.

7 Dahlöf B, Lindholm LH, Hansson L, Schersten B, Ekbom T, Wester P-O. Morbidity and mortality in the Swedish trial in old patients with hypertension (STOP-Hypertension). Lancet 1991;338:1281-5.

8 MRC Working Party. Medical Research Council trial on treatment of hypertension in older adults: principal results. $B M \Im$ 1992;304:405-12.

9 MRC Working Party. Stroke and coronary heart disease in mild hypertension: risk factors and the value of treatment. $B M \mathcal{F} 1988 ; 296: 1565-70$.

10 Mancia G, Parati G, Pomidossi G, Grassi G, Casadei R, Zanchetti A. Alerting reaction and rise in blood pressure during measurement by physician and nurse. Hypertension 1987;9:209-15.

11 Julius S, Jamerson K, Gudbrindsson T, Schork N. White coat hypertension: a follow-up. Clin Exp Hypertens [A] 1992;A14:45-53.

12 Mancia G. Ambulatory blood pressure monitoring: research and clinical applications. F Hypertens 1990:8(suppl 7):S1-S13.

13 Zanchetti A. What blood pressure level should be treated? In: Laragh JH,
Brenner BM, eds. Hypertension: pathophysiology, diagnosis, and management. .

14 Kannel WB, Dawber TR, McGee DL. Perspectives of systolic hypertension: the Framingham study. Circulation 1986;61:1179-82.

15 MRC Working Party on Mild to Moderate Hypertension. The MRC mild hypertension trial: some subgroup results. In: Strasser T, Ganten D, eds. Mild hypertension: from drug trials to practice. New York: Raven Press, 1987:9-20.

16 Joint National Committee on Detection, Evaluation, and Treatment of High Blood Pressure. The fifth report of the joint national committee on detection, evaluation, and treatment of high blood pressure (NCV). Arch Intern Med 1993;153:154-83.

17 WHO Expert Committee. Arterial hypertension. World Health Organ Tech Rep Ser 1978;628.

18 Zanchetti A. Goals of antihypertensive treatment: prevention of cardiovascular events and prevention of organ damage. Blood Pressure 1992;1:205-11.

19 Levy D, Garrison RJ, Savage DD, Kannel WB, Castelli WP. Prognostic implications of echocardiographically determined left ventricular mass in the Framingham heart study. N Engl f Med 1990;322:1561-6.

20 Koren MJ, Devereux RB, Casale PN, Savage DD, Laragh JH. Relation of lef ventricular mass and geometry to morbidity and mortality in uncomplicated essential hypertension. Ann Intern Med 1991;114:345-52

21 Shulman NB, Ford CE, Hall WD, Blaufox MD, Simon D, Langford HG, et al. Prognostic value of serum creatinine and effect of treatment of hypertension on renal function. Hypertension 1989;13(suppl 1):80-93.

22 Ruilope LM. Proteinuria and renal function. High Blood Pressure 1993;2(supp 1):50-3.

23 Parving H-M, Hommel E. Prognosis in diabetic nephropathy. BMf 1989;299. 230-3.

24 Cruickshank JM, Thorp JM, Zacharias FI. Benefits and potential harm of lowering high blood pressure. Lancet 1987;i:581-4.

25 The HOT Study Group. The hypertension optimal treatment study (the HOT study). Blood Pressure 1993;2:62-8.

26 WHO/ISH Guidelines Committee. Prevention of hypertension and associated cardiovascular disease: a 1991 statement. Clin Exp Hypertens [A] 1992;14: 333-41.

27 Layde PM, Beral V, Kay CR. Further analysis of mortality in oral contraceptive users. Royal College of General Practitioners' oral contraception study. Lancet 1981;i:541-6.

28 Wren BG, Routledge DA. Blood pressure changes: oestrogens in climacteric women. Med f Aust 1981;2:528-31.

29 Zanchetti A, Sleight $P$, Birkenhäger W/H. Evaluation of organ damage in hypertension. Consensus document. High Blood Pressure 1993;2(suppl 1):92-104.

(Accepted 22 September 1993)

\title{
Minimally Invasive Surgery
}

TNO Health Research, Center for Medical

Technology,

Zernikedreef 9,

2300 AK Leiden,

Netherlands

H David Banta, senior

researcher

BMF 1993;307:1546-9

\section{Implications for hospitals, health workers, and patients}

\author{
H David Banta
}

Minimally invasive surgery is one of the great innovations of health care in the 20th century. It promises to revolutionise surgery by allowing many more operations to be performed with minimal hospitalisation. Pressure from patients has caused many techniques to spread rapidly before they have been adequately assessed. This must be resisted, and policy makers must pay more attention to minimally invasive surgery to ensure that good assessments are made. The widespread use of minimally invasive techniques has important implications for hospitals and health workers. As more patients are treated on an outpatient basis, fewer hospital beds will be needed, and traditional operating rooms will have to adapt to a greater turnover of patients. Surgeons will have to acquire new operating skills, possibly requiring formal training and accreditation, and, as different specialties fight for control of new technologies, surgery may eventually be merged with internal medicine so that specialists will deal with organ systems. Postoperative care will have to be carried out in the community rather than in hospitals, and policy makers will need to reorganise their health systems to cope with these developments.

Minimally invasive surgery covers techniques from many specialties of medicine and surgery. The key innovation is the treatment endoscope. In addition, vascular catheters have brought alternatives to open surgery on arteries, including coronary arteries, and advanced medical imaging methods such as computed tomography have brought other possibilities such as draining abscesses through needles without open surgery. As part of a project sponsored by the European Commission, we collected a list of promising procedures in minimally invasive surgery and found that nearly all surgical procedures could be partially or totally replaced by less invasive alternatives.

An example of the changes that may be wrought by such techniques is the development of laparoscopic cholecystectomy, which may have spread more rapidly than any other health care technology. ${ }^{2}$ This technique began in France in 1987, ${ }^{3}$ and by 1988 it was already being done in the United States and other countries. ${ }^{4}$ As people with gall bladder problems learnt about the new procedure they refused to accept the traditional open surgery, for which four to six weeks of recuperation was necessary, associated with considerable pain and other problems.5 The laparoscopic procedure requires only a short hospital stay, in the United States it may be done without an overnight stay in hospital, ${ }^{67}$ and it allows a return to normal activities within a few days. In the future almost all gall bladder removals will surely be done by this method. It is certainly less traumatic and also appears to be safer, especially in skilled hands. ${ }^{68}$

\section{Problems with the spread of minimally invasive techniques}

The problem with laparoscopic cholecystectomy was that it spread into use without careful evaluation. Surgeons adopted it under pressure from patients 